\title{
O LOBBY DA CONFEDERAÇÃO NACIONAL DA INDÚSTRIA NA EDUCAÇÃO PROFISSIONAL BRASILEIRA
}

\author{
EL LOBBY DE LA CONFEDERACIÓN NACIONAL DE LA INDUSTRIA EN LA \\ EDUCACIÓN PROFESIONAL BRASILEÑA
}

\author{
THE LOBBY OF THE NATIONAL INDUSTRIAL CONFEDERATION IN \\ THE BRAZILIAN PROFESSIONAL EDUCATION
}

\author{
Jefferson Carriello do CARMO ${ }^{1}$ \\ Fernando Silveira Melo Plentz MIRANDA ${ }^{2}$
}

RESUMO: A intensão desse texto é identificar os objetivos dos empresários brasileiros quando fazem lobby no Congresso Nacional e quais as suas consequências para a educação brasileira, mais especificamente para a Educação Profissional (EP). O caminho escolhido para essa apreciação foi bibliográfico e documental, de cunho histórico e teórico-analítico. O período da análise é a nova república como um momento de crise orgânica. Nesse período foi identificado uma série de práticas empresariais processadas, por meio de um conjunto de inovações, que passam pelo campo econômico, político, e educacional, cuja finalidade é constituir novas formas de consenso hegemônico no Brasil, por meio do Lobby.

PALAVRAS-CHAVE: Políticas educacionais. Educação profissional. História da educação. Empresário industrial. CNI.

RESUMEN: La intensión de este texto es identificar los objetivos de los empresarios brasileños cuando hacen lobby en el Congreso Nacional y cuáles sus consecuencias para la educación brasileña, más específicamente para la Educación Profesional (EP). El camino escogido para esa apreciación fue bibliográfico y documental de cuño histórico, teóricoanalítico. El período del análisis es la nueva república, como un momento de crisis orgánica. En ese período se identificó una serie de prácticas empresariales procesadas, a través de un conjunto de innovaciones, que pasan por el campo económico, político, y educativo, cuya finalidad es constituir nuevas formas de consenso hegemónico en Brasil, a través del Lobby.

PALABRAS CLAVE: Políticas educativas. Educación professional. Historia de la educación. Empresario industrial. CNI.

\footnotetext{
${ }^{1}$ Universidade de Sorocaba (UNISO), Sorocaba - SP - Brasil. Doutor e Mestre em Educação, UNICAMP, PósDoutor em História Social do Trabalho, UNICAMP. Professor pesquisador do Programa de Pós-Graduação em Educação, Universidade de Sorocaba - UNISO. Líder e pesquisador do Grupo de estudos Instituição Escolar: história, trabalho e políticas de educação profissional-CNPq. ORCID: https://orcid.org/0000-0002-6816-5667. Email: jeffccprof@gmail.com; jefferson.carmo@prof.uniso.br

${ }^{2}$ Universidade de Sorocaba (UNISO), Sorocaba - SP - Brasil. Doutor em Educação e Mestre em Direito. Professor e Coordenador do Curso de Direito da UNISO. Pesquisador do grupo de estudos Instituição Escolar: história, trabalho e políticas de educação profissional - CNPq. ORCID: https://orcid.org/0000-0001-5110-4545. E-mail: fernando.plentz@prof.uniso.br; fernandomiranda.adv@bol.com.br
} 
ABSTRACT: The intention of this text is to identify the Brazilian businessmen's objectives doing the lobby in the National Congress and their consequences for the Brazilian education, specifically for the Professional Education (PE). The chosen path for this appreciation was bibliographic and historical documentary, theoretic-analytical. The period of analysis is the new republic, as a moment of organic crisis. In this period was identified a series of processed business practices, by means of a set of innovations, that pass through the economic, political and educational field, which finality is to constitute new ways of hegemonic consensus in Brazil, through the lobby.

KEYWORDS: Educational policies. Professional education. Education's history. Industrial manager. CNI.

\section{Introdução}

A intensão desse texto é identificar os objetivos dos empresários brasileiros quando fazem lobby através Estado e quais as suas consequências para a educação brasileira, mais especificamente para a Educação Profissional (EP), no período da nova república. O caminho escolhido para essa apreciação foi bibliográfico e documental, de cunho histórico e teóricoanalítico.

$\mathrm{Na}$ análise de Coutinho (2006) em Estado brasileiro: gênese, crise, alternativas, o período da nova república é um momento de crise orgânica, isto é, um tempo em que a crise econômica e o poder político das classes se contradizem em um processo de transição, imprimido novos perfis para as práticas sociais de classe. Nesse período, segundo Figueiredo (2009), é possível identificar uma série de práticas empresariais processadas por meio de um conjunto de inovações, que passam pelo campo econômico, político, e educacional, cuja finalidade e constituir novas formas de consenso hegemônico no Brasil.

Segundo as apreciações de Diniz e Boschi (1993), as mudanças no modo de pensar do empresariado brasileiro estiveram associadas, também, à crise de suas representações, na década de 1980. A consequência disso foi o surgimento de um elevado número de entidades empresariais, cujo objetivo foi a articulação do empresariado em torno de interesses mais amplos, com a finalidade de superar o corporativismo, marca visível dos órgãos de representações oficiais dos empresários.

Nos anos de 1990, esse segmento empresarial, mais organizado, mostra-se mais atuante e com maior articulação, pela razão das mudanças ocorridas da fusão do capital bancário com o industrial, da participação do capital estrangeiro nas empresas nacionais. Nesse contexto da nova república, os empresários se inserem de forma ativa na arena política, onde uma de suas ações é fazer lobby. 
Segundo a análise de Diniz e Boschi (1993), os empresários passaram a ter uma presença mais ativa na arena política propriamente dita, disputando cargos eletivos em diferentes níveis. Essa presença ocorre pela eleição de uma bancada expressiva para o Congresso Constituinte vindo representar vários estados e municípios.

No campo educacional, vários estudos mostram a relação e a posição do empresariado com a educação. Nos estudos de Neves (1994; 2000a; 2000b), há evidências na relação e posição do empresariado frente à temática educacional nos anos de 1980, como também no início da década de 1990 e nos anos posteriores. Nesses períodos os vários autores identificam os empresários industriais no Brasil e as formas pelas quais se reestruturaram politicamente para alcançar maior capacidade de intervenção na agenda das políticas públicas sociais e de EP (MORAES, 2013; KRAWCZYK, 2014; MELO, 2009 e outros).

Nas análises de Oliveira, em vários momentos sobre as políticas de EP (2003; 2005; 2006a; 2006b; 2010) o projeto empresarial de desenvolvimento econômico no final do século XX e início do século XXI vê na educação profissional um papel fundamental para a economia, nesse período. No exame realizado por meio dos documentos técnicos da Confederação Nacional da Indústria (CNI), da Federação das Indústrias do Estado de São Paulo (FIESP), do Programa Ibero-americano de Cooperação para o Desenho Comum da Formação Profissional (Programa IBERFOP) e pelas Agências Multilaterais, identifica a atuação das lideranças empresariais nos diversos campos, inclusive na educação de formação para o trabalho.

Essas considerações iniciais serão vistas, com mais detalhes, por meio dos seguintes itens: reorganização dos empresários industriais a partir da Nova República; formação por competência: fundamento do pensamento pedagógico da CNI; Grupos de interesse: o lobby da CNI junto à legislação que regulamenta a educação brasileira.

\section{Reorganização dos empresários industriais a partir da Nova República}

Diniz (1997) indica que com o advento da Nova República iniciada no Governo Sarney, o empresariado industrial sofre um processo de reestruturação e substituição de lideranças, que fortalecem as entidades sindicais patronais da indústria, destacando-se uma nova articulação da CNI com o Governo Federal, mais pautada na autonomia e na relação de interesses da Confederação junto ao Estado do que na interferência direta do Estado na sua estrutura administrativa, como ocorria nos Governos militares.

Esta nova articulação dos empresários industriais é incorporada pela CNI, que passa a atuar na defesa dos interesses da indústria junto ao Governo Sarney, manifestando-se tal 
influência através de uma nova legislação para o setor industrial, que agrupa as necessidades de modernização da indústria brasileira sob o eixo comum do desenvolvimento industrial a partir de programas de desenvolvimento de tecnologia, formação de mão de obra, redução de alíquotas de importação, entre outros.

Portanto, o que desejava o Governo Sarney com estas políticas públicas de incentivo, apoiado pela CNI, era modernizar o parque industrial brasileiro, adequando-o à complexidade industrial atrelada à eletrônica e à microinformática. Tais incentivos permitiram a instalação de empreendimentos nos setores de informática, telecomunicações e eletrônica de consumo que fossem capazes de atender as necessidades da indústria nacional e do mercado consumidor.

Diniz (2002) destaca que, apesar das tentativas de modernização das políticas industriais dos Governos Sarney, Collor e Itamar, a implantação de uma política industrial voltada ao mercado que tenha conseguido algum êxito somente ocorreu a partir de 1995, sob o Governo Fernando Henrique Cardoso, que contou com apoio da CNI e das federações industriais estaduais. No período entre 1995 e 1997, o Brasil se insere de vez no mercado internacional globalizado, adotando uma série de políticas de estabilização e reformas, com o incentivo à privatização com tendências à eliminação do Estado-empresário, abertura comercial e liberalização de fluxos financeiros.

Esta profunda reestruturação do Estado brasileiro atingiu a indústria nacional, que mudou o seu perfil nos anos 1990 através de associações com empresas estrangeiras, fusões, aquisições e falências, afetando mais diretamente as indústrias têxtil, de máquinas e equipamentos, autopeças e produtos eletroeletrônicos.

O ambiente empresarial nos anos 1990 sofre uma drástica alteração em comparação com as décadas anteriores, inserindo as indústrias no mercado competitivo globalizado. Neste sentido, o perfil das indústrias nacionais se modifica para se adaptar à globalização e para conseguir uma vantagem competitiva no mercado nacional e internacional, entre elas: primeiro, condições de fatores (fatores naturais, infraestrutura e mão de obra especializada); segundo, condições de demanda (demanda interna por produtos e serviços); terceiro, indústrias correlatas e de apoio (clusters); quarto, estratégia industrial (embora as empresas sejam rivais, devem encontrar um eixo comum e persegui-lo, notadamente através da estrutura sindical patronal).

Dessa forma, se antes da década de 1980 os empresários industriais tinham uma baixa capacidade de agir coletivamente perante o Estado em face da intervenção dos Governos militares na estrutura administrativa da CNI, a partir dos anos 1990 os industriais se reestruturam e superam os problemas de ação coletiva. Segundo Mancuso (2007), a ação coletiva dos empresários industriais ocorre através da atuação sistemática da CNI, que nos anos 
1990 passa a adotar uma agenda comum aos empresários industriais, na denominada "redução do custo Brasil", participando e influenciando os eventos políticos mais relevantes do país, dentre eles o lobby junto ao Congresso Nacional na elaboração das leis.

Assim, no decorrer dos anos 1990, ao passo em que o Governo FHC realizava a reforma do Estado brasileiro, a CNI enquanto órgão máximo de representação sindical do empresariado industrial incorporou o ideário de mudanças e conseguiu, em face de uma agenda comum a todos os industriais brasileiros, sintetizar a confluência de interesses dos seus associados e influenciar o Governo.

\section{Formação por competência: fundamento do pensamento pedagógico da CNI}

Formulada por Schultz na década de 1960, a Teoria do Capital Humano (TCH) indica que o progresso de uma nação decorre do investimento direto do investimento em educação e na qualificação dos indivíduos.

Schultz (1967), ao avaliar as relações entre capital e trabalho nos Estados Unidos da América dos anos 1960, indica que os acréscimos que ocorriam na produção industrial estavam associados à percepção de que as pessoas investem em si mesmas como ativos humanos, sendo, portanto, a educação a base da TCH. O aumento da produção é explicado pelo fator humano que incrementa a produtividade do trabalhador, passando então este fator humano a ser considerado capital. A educação passa então a ter valor econômico, pois a instrução é o maior investimento do capital humano.

Definindo a TCH, Schultz (1967, p. 18) conceitua educação e a associa à indústria:

Recomendo que a educação seja considerada como um conjunto de atividades: algumas das quais organizadas, conforme se apresentam nas escolas, e outras essencialmente desorganizadas, segundo ocorre com a educação familiar. [...] a educação é uma atividade que gera conhecimentos e, em decorrência, prossegue classificando essa educação o que se realiza: no lar; na igreja; no serviço militar; nas empresas, constante de instrução prática; e, nas escolas, notadamente, primárias, secundárias e institutos de educação superior. As escolas podem ser consideradas empresas especializadas em "produzir" instrução. A instituição educacional, que congrega todas as escolas, pode ser encarada como uma indústria.

O objetivo da TCH é influenciar positivamente as taxas de crescimento dos países ao aprimorar em larga escala as habilidades da força de trabalho dos indivíduos através da educação. Assim, a educação se torna uma espécie do capital, um componente da produção, que ao ser investido, estará baseado na lógica capitalista de investimento e custo, portanto, dependendo de retorno e lucro. 
Ramos (2006) demonstra que diante da acumulação flexível e dos novos sistemas produtivos que decorrem das mudanças tecnológicas e de organização do trabalho, os empresários passam a demandar novas qualificações dos trabalhadores, adquirindo forte relevância a noção de competência. A partir de então, o que se processa no seio da produção capitalista é a qualificação dos trabalhadores como relação social, adequando a sociedade aos requerimentos econômicos do século XXI. Aponta a autora que a competência atende a, no mínimo, três propósitos: primeiro, reordenar o entendimento da relação trabalho-educação transferindo para o trabalhador a responsabilidade por qualificar-se segundo as suas próprias implicações subjetivas para o trabalho; segundo, institucionalizar as novas maneiras de educar e formar os trabalhadores, gerindo o trabalho às necessidades das organizações e dos mercados seguindo novos códigos profissionais; e, terceiro, definir padrões que possam identificar, validar e certificar a capacidade do trabalhador para determinada ocupação.

Cavalcante (2009), ao descrever que a orientação educacional da CNI está embasada na $\mathrm{TCH}$, indica que esta teoria é a mais apropriada para a indústria, que passa a utilizá-la como fundamento pedagógico. Destaca que estes conceitos são absorvidos pela indústria no setor produtivo e de contratação de mão de obra, demonstrando também a necessidade de um vínculo funcional entre a pesquisa acadêmica e a empresa industrial, colocando a primeira como instrumento de processamento e análise dos dados colhidos pela segunda, admitindo que a educação esteja a serviço da indústria, para formar mão de obra apta a exercer funções compatíveis com os elevados níveis de tecnologia presentes nas novas formas de produção industrial.

O alinhamento da CNI à TCH desde os anos 1990 é demonstrado na série de documentos emitidos de forma sistemática com o intuito vincular produção, mercado de trabalho e educação (CNI, 1993; 1997).

Sob esta mesma orientação, já no século XXI, a CNI $(2013$, p. 8) afirma que:

As exigências da qualificação em diversos setores aumentam a cada dia. O progresso tecnológico demanda novas competências. Em 2025, uma grande parte dos nossos trabalhadores terão de lidar com tecnologias que ainda nem foram criadas.

Não é tarefa simples mobilizar um país de tamanho continental como o Brasil para que alcance padrões adequados de qualificação educacional, em todas as etapas e modalidades, em prazo compatível com a urgência que requer a indústria nacional. Demanda tempo, persistência e principalmente, comprometimento da sociedade e dos governos nas esferas federal, estadual e municipal. Se bem sucedido, o processo pode levar, em média, o tempo de uma geração escolar - 20 anos. Assim, ocorreu em países que deram saltos de qualidade na sua educação, adotando políticas públicas consistentes e sem solução de continuidade. 
As novas tecnologias produtivas requerem do trabalhador domínio de conhecimentos e habilidades que se adquirem por meio de uma adequada educação básica, à qual se associa, quando necessária, a uma qualificação profissional específica.

Desta forma, a CNI busca difundir na sociedade brasileira desde os anos 1990 a ideia de que, para o desenvolvimento econômico e social do Brasil, é necessária uma nova institucionalidade nacional, que permita às indústrias alcançarem um novo patamar de competitividade e eficiência industrial, sendo a educação um dos pilares desta nova institucionalidade.

\section{Grupos de interesse: o lobby da CNI junto à legislação que regulamenta a educação brasileira}

Esclarece Diniz (1997, p. 106) que os empresários industriais exerceram destacada influência no plano político desde os anos 1980, ao apoiar a Nova República e candidatos à Câmara dos Deputados e ao Senado Federal, garantindo espaço nos debates no Congresso Nacional Constituinte:

[...] as lideranças empresariais utilizariam os canais partidários, candidatandose a cargos executivos e legislativos, prontos a ocupar os espaços disponíveis e a ampliar seus recursos de poder. Observou-se ainda a generalização da prática do lobby empresarial, que veio a se consagrar como uma modalidade rotineira de pressão. Durante o Congresso Constituinte, esse estilo de atuação via lobby passou a ocupar espaço cada vez maior, em função não só da importância assumida pela atividade parlamentar, mas também do fechamento crescente das arenas de representação corporativa na burocracia governamental.

Ressalta Diniz (1997) que o principal objetivo da CNI era participar dos debates legislativos referentes à ordem econômica, aos direitos trabalhistas e à organização sindical, atuando como grupo de pressão e exercendo lobby junto aos parlamentares constituintes na defesa dos seus interesses. A efetividade deste movimento da CNI se demonstra na percepção de que o texto da Constituição Federal de 1988 (CF/88)(BRASIL, 1988) normatizou no texto constitucional inúmeras das suas solicitações, garantindo o regime da livre iniciativa (livre empresa), manteve a unicidade sindical (agregando todos os empresários industriais brasileiros na $\mathrm{CNI}$ ), reduziu a jornada de trabalho de 48 para 44 horas semanais (havia um movimento para reduzir para 40 horas semanais) e garantiu a defesa da negociação coletiva de trabalho através dos sindicatos econômicos e profissionais. 
Observa Diniz (2002) que o cerne da atuação dos empresários industriais no período anterior à Nova República esteve voltado principalmente para o Poder Executivo, no sentido de controlar ou influenciar a burocracia estatal voltada à formulação e implementação de políticas públicas, mas que, desde a redemocratização, também há um movimento dos industriais em direção ao Congresso Nacional. Desde a legislatura que elaborou a CF/88, os empresários industriais exercem lobby junto aos congressistas, especialmente em determinados períodos que despertam intensa mobilização de atividades parlamentares para votações de impacto aos interesses dos industriais.

Mancuso (2007) destaca que a prática do lobby ganha espaço de representação política no Brasil após o período de redemocratização, na década de 1980, momento em que o Poder Legislativo passa a ser relevante no cenário político nacional. Explica que o lobby se torna uma atividade habitual, através do qual os grupos de interesse buscam participar do processo estatal de tomada de decisões, influenciando os agentes políticos na elaboração de políticas públicas. Assim, o lobby é a prática do exercício de influência no contexto da democracia representativa, visando aproximar as condutas dos representantes formais eleitos pela sociedade, sejam dos Poderes Legislativo ou Executivo, aos objetivos e valores de determinado grupo de interesse, garantindo-se o conjunto ideológico restritivo dos mesmos.

O lobby é, então, um meio através do qual determinado grupo de interesse transmite aos tomadores de decisões políticas as informações das suas necessidades específicas, para que as decisões provindas do Poder Público venham beneficiar o grupo de interesse. Para o sucesso do lobby, os grupos de interesse se utilizam de meios de comunicação e fundamentam seus ideais e necessidades através de levantamento de dados, pesquisas e elaboração de propostas.

Mancuso e Gozetto (2011) afirmam que o lobby é a atividade de defesa de interesses afetados por decisões públicas, podendo ser realizado lícita ou ilicitamente. Apontam que muitas vezes o lobby está associado à defesa ilícita de interesses, resultando em crimes contra a administração pública, tais como corrupção, tráfico de influência, fraudes em concorrência, etc. Contudo, ao defenderem o lobby lícito, alegam que este pode refinar a opinião pública ao fornecer informações e fomentar os debates de questões relevantes que são postas à agenda decisória do poder público. Amparam o lobby lícito pois entendem que há dois aspectos positivos do lobby: primeiro, pode aproximar os resultados decisórios das necessidades dos interesses organizados; segundo, pode proporcionar aos grupos de interesse participar do debate político, mediante defesa pública e aberta dos seus ideais e objetivos, enriquecendo o debate público sobre assuntos relevantes.

Esclarecem Mancuso e Gozetto (2011, p. 123) que: 
[...] o lobby lícito pode beneficiar o sistema político como um todo. Primeiramente, o lobby em defesa de "grandes causas" (por exemplo, o desenvolvimento sustentável e o combate à corrupção na política) contribui diretamente para a satisfação do interesse público. Além disso, o lobby lícito fortalece o sentimento de pertença dos interesses organizados à comunidade política, colaborando para legitimar a própria comunidade e seu poder público. Ao criar um canal de comunicação entre os interesses organizados e o poder público, o lobby lícito contribui para a legitimação do sistema político, pois assegura que as demandas de relevantes interesses sociais serão efetivamente consideradas durante os processos decisórios - na ausência desse canal, a legitimidade do sistema político poderia vir a ser contestada.

A questão fundamental que se coloca ao lobby lícito é em relação ao problema da igualdade política. É notório que segmentos sociais diferentes não são capazes de se organizar e arregimentar recursos para formar seus lobbies da mesma forma. Neste sentido, o lobby dos empresários industriais é bem-sucedido por dois aspectos: primeiro porque estes empresários organizam uma agenda comum através da CNI, resolvendo o impasse da ação coletiva e, segundo, conseguem aglutinar recursos financeiros suficientes para efetuar sólidos estudos técnicos, realizar campanhas publicitárias e contratar talentosos e influentes lobistas.

Mancuso (2007) constata que a CNI, desde os anos 1990, desempenhou um grande trabalho de identificação dos projetos nacionais de maior impacto no cotidiano e futuro da indústria nacional, elaborando numerosos documentos que acabam por influenciar a tomada de decisões dos agentes políticos brasileiros.

No bojo da globalização, a CNI defende a entrada do Brasil no mercado internacional, e, nos anos 1990, integra-se à lógica da globalização econômica, política e cultural, na busca de um novo padrão de desenvolvimento capitalista fundamentado na acumulação flexível e pela flexibilização das relações de trabalho.

Neste contexto, a ação coletiva do empresariado industrial organizado pelas ações e documentos da CNI passa a defender as políticas neoliberais e a exercer lobby para a reforma do Estado, a ser efetivado por um conjunto de novas leis que regulamentem estas mudanças, dentre elas a legislação educacional.

Para os empresários industriais (CNI, 1993) a educação se torna um ponto fundamental no processo de construção de uma economia mais competitiva, posto que incentiva a formação de novas competências aos trabalhadores que se inserem com maior facilidade e flexibilidade no mercado de trabalho, com ganhos de produtividade para a indústria. Assim, desde os anos 1990, para a CNI a melhoria da qualidade da educação e o aprimoramento da qualificação dos trabalhadores deixam de ser apenas uma questão de Estado e tornam-se fatores fundamentais no processo de modernização industrial, fazendo com que a CNI se tornasse um sujeito 
participante do processo educacional brasileiro, exercendo influência nos poderes do Estado através do lobby.

Neste sentido, o discurso legislativo que regulamentou os novos parâmetros da educação brasileira está impregnado pela influência do pensamento neoliberal e do empresariado industrial, inclusive na época da edição da Lei de Diretrizes e Bases da Educação Nacional (LDBEN/96) (BRASIL, 1996), definindo que competia à educação cumprir um papel econômico estruturado no "aprender a conhecer", "aprender a fazer" e "aprender a ser". Em consequência disso, a noção de empregabilidade ganha força no Brasil no decorrer dos anos 1990, seja nas orientações dos empresários industriais através dos documentos emitidos pela CNI, seja por meio dos textos legais aprovados pelo Congresso Nacional ou editados pela Presidência da República no decorrer dos anos 1990

A LDBEN/96 se estrutura na flexibilidade curricular e na avaliação da educação, descentralizada no exercício cotidiano da educação escolar e centralizada e institucionalizada na sua estrutura avaliativa. Em outras palavras, a LDBEN/96 agrada os empresários industriais, que defendem a vinculação entre educação e produtividade, prevendo autonomia da escola na sua atuação diária e flexível às realidades e necessidades locais, mas que é controlada pelo Governo, que centraliza as formas de avaliação.

Uma vez definida a nova diretriz educacional no Brasil, a CNI passa a influenciar o Estado para que as regulamentações posteriores seguissem os mesmos parâmetros. Em relação às características que os trabalhadores deveriam possuir para atender aos interesses dos industriais, o documento da CNI (1997) deixa claro que a produção industrial de caráter flexível exige polivalência dos trabalhadores, em outras palavras, que esteja capacitado para o desempenho de várias tarefas. Para isso, a flexibilidade que o trabalhador necessita para desempenhar as suas funções laborais na indústria deve ser conquistada via capacitação da educação profissional, estando a educação básica como precondição ao bom desempenho da educação profissional. Portanto, a educação básica e a educação profissional passam a ser uma prioridade para a CNI, argumentando que os sistemas educacionais devam estar atentos às mudanças no mundo do trabalho.

O resultado do pensamento e do lobby da CNI ocorre quando o Governo FHC edita o Decreto $n^{\circ}$. 2.208/1997 (BRASIL, 1997), que passa a regulamentar a educação profissional brasileira, radicalizando a separação entre ensino médio "acadêmico" e o ensino profíssional, denominado de forma mais ampla por "educação profissional", conforme constava na LDBEN/1996. Assim, sob a perspectiva de adotar uma política educacional voltada às necessidades do capital e da indústria, o Governo FHC regulamentou o artigo $36, \S 2^{\circ}$ da 
LDBEN/1996, através da edição do Decreto $n^{\circ}$. 2.208/1997 que reformou a educação profissional brasileira.

Assim, pelo Decreto nº 2.208/1997 fica estabelecido o caráter independente e separado da educação profissional do ensino médio, em face do disposto pelo artigo $2^{\circ}$ do referido Decreto, ao estabelecer que a educação profissional será desenvolvida "em articulação" com o ensino regular e não integrada a ele, institucionalizando-se a separação do ensino médio do ensino profissional, ou seja, a dualidade educacional.

Na análise de Frigotto (2000), o Decreto nº 2.208/1997 é a exacerbação do dualismo e da fragmentação educacional, com a notória separação das dimensões técnicas, específicas e particulares de um lado e, de outro, das dimensões políticas, gerais e universais da educação. Afirma que, sob um pretexto falso de custos elevados e de que a educação profissional estaria atendendo a uma elite social e não aos trabalhadores, o Governo FHC editou tal Decreto instaurando um processo de desmantelamento do ensino técnico médio e de privatização deste ramo educacional, inserido no ajuste das reformas neoliberais dos anos 1990 e como mecanismo de subordinação da educação aos ditames do mercado.

Na perspectiva de oferecer uma crítica ao modelo de educação profissional estabelecida pelo Decreto $n^{\circ}$. 2.208/1997, Frigotto (2001) afirma que sob o poder hegemônico do capital se constrói um suposto novo paradigma na educação para os trabalhadores, embasado na ética individualista que se manifesta sob os conceitos de competências, competitividade, habilidades, qualidade total, empregabilidade, mas que, sob o aspecto social, gera o individualismo e a desagregação do conhecimento integral que se espera para o crescimento intelectual e social dos indivíduos. Em outras palavras, a edição do Decreto $n^{\circ}$. 2.208/1997 sob o prisma da vinculação da educação às necessidades do mercado de trabalho, em especial a formação do trabalhador ao trabalho industrial, está inserido na lógica da formação de um novo cenário industrial projetado pelo Governo FHC, sob a influência do lobby da CNI.

A partir do início do Governo Lula, o Brasil vivencia um momento de reconstrução do protagonismo do Estado como agente capaz de impulsionar e organizar o desenvolvimento econômico e social do país, empreendendo um esforço de implantação de novos arranjos institucionais de orientação da ação estatal.

O Governo Lula reafirmou os compromissos assumidos que o elegeram e, no que compete à educação profissional, inicia o debate público que implicaria na reconstrução da política pública destinada a este ramo educacional, visando à correção das distorções, dos conceitos e das práticas decorrentes das medidas adotadas pelo Governo FHC. Novos paradigmas legais passam a ter vigência neste período, sendo o Decreto $\mathrm{n}^{\circ}$. 2.208/1997 
revogado pelo novo Decreto $n^{\circ}$. 5.154/2004, que passa a regulamentar a LDBEN/1996 no que concerne à educação profissional.

Contudo, durante o Governo Lula houve uma íntima parceria entre a burocracia pública federal e os empresários industriais na elaboração de uma agressiva política industrial no processo de internacionalização de empresas privadas brasileiras. Os empresários industriais dos setores em que a indústria brasileira já era competitiva, tais como a construção civil e a indústria associada aos recursos naturais, foram as mais beneficiadas. Com efeito, os empresários industriais com as bênçãos da CNI foram claramente beneficiados pelas políticas públicas tomadas a cabo durante o Governo Lula. (SAAD FILHO; BRAGA, 2012; PAULANI, 2008)

Inobstante aos ideais de fim da dualidade na educação profissional previstos no Decreto $\mathrm{n}^{\mathrm{o}}$. 5.154/2004, Rodrigues (2005) declara que este Decreto fora editado tão somente para acomodar interesses em conflito, agradando os setores progressistas que apoiavam o Governo Lula e, ao mesmo tempo, mantendo a dualidade educacional através da formação concomitante ou sequencial, condizentes com o modo de produção atual, representando, desta forma, a permanência dos princípios basilares de dualidade educacional constante na regulamentação anterior. Neste sentido, percebe-se que o lobby da CNI obteve os resultados esperados pelos empresários industriais, posto que seja qual for o governo ou a regulamentação legal vigente, os interesses dos industriais prevalecem.

\section{Considerações finais}

Esse texto, considerando seu objetivo, mostrou que a educação profissional sofre influência dos empresários industriais através da CNI. Foi identificado nos documentos da CNI que o empresariado busca influenciar o Estado por meio do lobby, cuja finalidade é a regulamentação da educação profissional, com vistas à formação de mão de obra "qualificada".

É perceptível o papel dos atores estatais - Governos - e não estatais, dentre eles os empresários, envolvidos na elaboração das políticas púbicas para a educação profissional estabelecidas pelo lobby e definindo o conteúdo do texto legislativo segundo os seus interesses.

A partir desta verificação, é possível dizer que em momento algum da história brasileira o Estado deixa de requerer para si próprio o controle da elaboração das políticas educacionais, posto que a tomada de decisão compete exclusivamente ao Governo. Porém, foi constado que o conteúdo das decisões governamentais varia no decorrer do tempo histórico, com a defesa 
dos interesses de determinados grupos mais influentes e organizados sendo exercida junto aos Governos através do lobby.

\section{REFERÊNCIAS}

BRAGA, Ruy. A política do precariado: do populismo à hegemonia lulista. São Paulo: Boitempo, 2012.

BRASIL. Constituição da República Federativa de 1988. Brasília: 1988.

BRASIL. Lei no . 9.394, de 20 de dezembro de 1996. Estabelece as diretrizes e bases da educação nacional.

BRASIL. Decreto $\mathbf{n}^{\mathbf{0}}$. 2.208, de 17 de abril de 1997. Regulamenta o $\S 2^{\circ}$ do art. 36 e os arts. 39 a 42 da Lei $n^{\circ}$ 9.394, de 20 de dezembro de 1996, que estabelece as diretrizes e bases da educação nacional.

BRASIL. Decreto $\mathbf{n}^{\mathbf{0}}$. 5.154, de 23 de julho de 2004. Regulamenta o $\S 2^{\circ}$ do art. 36 e os arts. 39 a 42 da Lei $n^{\circ} 9.394$, de 20 de dezembro de 1996, que estabelece as diretrizes e bases da educação nacional, e dá outras providências.

CAVALCANTE, Neusa. 40 anos do IEL na trajetória da indústria no Brasil. Brasília: IEL, 2009.

CONFEDERAÇÃO NACIONAL DA INDÚSTRIA. Educação básica e formação profissional: uma visão dos empresários. Rio de Janeiro: CNI/SENAI, 1993.

CONFEDERAÇÃO NACIONAL DA INDÚSTRIA. Educação para o mundo do trabalho: Documento Conceitual. Brasília: CNI, 2013.

CONFEDERAÇÃO NACIONAL DA INDÚSTRIA. Emprego na indústria: evolução recente e uma agenda de mudanças. Rio de Janeiro: CNI, 1997.

COUTINHO, Carlos Nelson. O Estado brasileiro: Gênese, crise alternativas. In: LIMA, Júlio César França, NEVES, Lúcia Maria Wanderley (Orgs.). Fundamentos da Educação Escolar do Brasil Contemporâneo. Rio de Janeiro: Editora Fiocruz/EPSJV, 2006.

DINIZ, Eli; BOSCHI, Renato. Brasil: um novo empresariado? Balanço de tendências recentes. In: DINIZ, Eli (org.). Empresários e modernização econômica: Brasil anos 90. Florianópolis: Ed. UFSC, IDACON, 1993.

DINIZ, Eli. Crise, reforma do Estado e governabilidade: Brasil, 1985-95. Rio de Janeiro: FGV, 1997.

DINIZ, Eli. Empresariado e estratégias de desenvolvimento. Lua Nova/Revista de cultura e política, n. 55, p. 241-262, 2002. 
FIGUEREDO, Ney (Org.) Empresariado brasileiro: política, economia e sociedade. São Paulo: Editora Cultura, 2009.

FRIGOTTO, Gaudêncio. Educação, trabalho e desenvolvimento: contradições da atual política educacional. Revista da Diretoria de Engenharia da Aeronáutica, v. 10, n. 18, p. 46-50, nov./2000.

FRIGOTTO, Gaudêncio. A nova e a velha crise do capital e o labirinto dos referenciais teóricos. p. 21-46. In: FRIGOTTO, Gudêncio; CIAVATTA, Maria (orgs.). Teoria e educação no labirinto do capital. Petrópolis: Vozes, 2001.

KRAWCZYK, Nora. Ensino médio: empresários dão as cartas na escola pública. Educação \& Sociedade., v. 35, n. 126, p. 21-41, mar. 2014.

MANCUSO, Wagner Pralon. O lobby da indústria no Congresso Nacional: empresariado e política no Brasil contemporâneo. São Paulo: Humanitas, 2007.

MANCUSO, Wagner Pralon; GOZETTO, Andréa Cristina Oliveira. Lobby: instrumento democrático de representação de interesses? Organicom, ano 8, n. 14, p. 118-128, 2011.

MELO, Alessandro de. Educação básica e formação profissional na visão dos empresários brasileiros. Educ. Soc., v. 30, n. 108, p. 893-914, out., 2009.

MORAES, Reginaldo Correa; SILVA, Maitá de Paula. O peso do Estado na pátria do mercado: os Estados Unidos como país em desenvolvimento. São Paulo: Unesp, 2013.

NEVES, Lúcia Maria Wanderley. Educação e política no Brasil de hoje. $2^{a}$ ed. São Paulo: Cortez, 1994.

NEVES, Lúcia Maria Wanderley (Org.) Educação e política no limiar do século XXI. Campinas, SP: Autores Associados, 2000a.

NEVES, Lúcia Maria Wanderley. Brasil 2000: nova divisão de trabalho na educação. $2^{a}$ ed. São Paulo: Xamã, 2000b.

OLIVEIRA, Ramon de. Empresariado industrial e educação Brasileira. São Paulo: Cortez, 2005.

OLIVEIRA, Ramon de. Agências Multilaterais e a Educação Profissional Brasileira. Campinas - SP: Alínea, 2006a.

OLIVEIRA, Ramon de. Educação e trabalho: do mito da reconversão tecnológica à ideologia da empregabilidade. Revista FAEEBA. v. 15, p. 57-66, 2006b.

OLIVEIRA, Ramon. Educação Profissional na Ibero-América: um estudo do programa IBERFOP. Educação e Realidade, Porto Alegre, v. 35, n. 3, p. 237-256, set./dez., 2010. Disponível em: http://seer.ufrgs.br/educacaoerealidade/article/viewFile/8809/10284. Acesso em: 19 mar. 2017. 
PAULANI, Leda. Brasil Delivery: servidão financeira e estado de emergência econômico. São Paulo: Boitempo, 2008.

RAMOS, Marise Nogueira. A pedagogia das competências: autonomia ou adaptação? 3. ed. São Paulo: Cortez, 2006.

RODRIGUES, José. O moderno príncipe industrial: o pensamento pedagógico da confederação Nacional da Indústria. Campinas, SP: Autores Associados, 1998.

RODRIGUES, José. Ainda a educação politécnica: o novo decreto da educação profissional e a permanência da dualidade estrutural. Rev. Trabalho e Saúde, v. 3, n. 2, p. 259-282, 2005.

SAAD, FILHO, Alfredo; MORAIS, Lecio. Brasil: neoliberalismo versus democracia. São Paulo: Boitempo, 2018.

SCHULTZ, Theodore William. O valor econômico da educação. Rio de Janeiro: Zahar, 1967.

\section{Como referenciar este artigo}

CARMO, J. C. do; MIRANDA, F. S. M. P. O lobby da Confederação Nacional da Indústria na educação brasileira. Revista Ibero-Americana de Estudos em Educação, Araraquara, v. 14, n. esp. 3, p. 1782-1796, out., 2019. E-ISSN: 1982-5587. DOI: 10.21723/riaee.v14iesp.3.12763

Submetido em: 25/03/2019

Revisões requeridas: 20/04/2019

Aceito em: 15/05/2019

Publicado em: 30/08/2019 